\title{
As marcas de SaVigny na doutrina civilista*
}

\section{Michel Boudot**}

\section{Introdução}

A partir da leitura dos civilistas franceses do fim do século XIX, como Saleilles, Bufnoir, Planiol, Gény e mesmo Baudry-Lacantinerie, não resta nenhuma dúvida: Savigny não apenas imprimiu sua marca à revolução metodológica que vivificou o direito romano, mas também foi um dos que desenvolveram teorias dominantes no direito civil. Da posse ao direito das obrigações, Savigny mostra-se, nos escritos dos titulares da escola da livre pesquisa científica, como um autor inevitável no século XIX francês.

Devemos, no entanto, ser comedidos: a presença de Savigny na literatura civilista do início do século XX e o papel dominante que lhe é atribuído pouco coincidem com as poucas marcas que ele deixou nos grandes comentários do século XIX. Os escritores da Thémis, seguramente, dedicaram-se a difundir o pensamento de Savigny, ${ }^{1}$ os romanistas foram, indubitavelmente, impregnados pela sua Teoria da posse em direito romano, ${ }^{2}$ Savigny teve, certamente, defensores de suas idéias e discípulos autoproclamados; ${ }^{3}$ mas as referências à sua obra nos tratados e comentários do direito civil francês, supreendentemente, permanecem parcas. ${ }^{4}$

De urn ponto de vista metodológico, para conjugar a construção da história do pensamento com as contribuições doutrinárias, não me empenhei em fazer muitas considerações de ordem biográfica; ${ }^{5}$ dado que os meus esforços arqueológicos limitaram-se aos aspectos literários, em verdade, a única obra de Savigny que eu possivelmente poderia encontrar na literatura civilista francesa anterior a 1840 é o Tratado daposse em direito romano. ${ }^{6}$ As coisas mudarão

\footnotetext{
* O artigo é versão escrita da palestra proferida no Colóquio "Les civilistes français face àl 'œuv re de Savigny - La Codification du droit, Savigny et la France" do Instituto Michel Villey, em 19 de outubro de 2007, na Universidade Paris II, Panthéon-Assas. Tradução livre e autorizada de Marcelo Boff Lorenzen (bolsista CAPES-Unibral, Giessen-UFRGS), estudante do $5^{\circ}$ ano da Faculdade de Direito da UFRGS, Porto Alegre; integrante do grupo de pesquisa CNPq "Mercosul e Direito do Consumidor", sob a coordenação da Prof. ${ }^{a} r^{2}$ Claudia Lima Marques. Revisão de Wellerson Miranda Pereira (Mestre em Direito pela Université de Lausanne - Suíça; doutorando em direito sob co-tutela pela Université de Savoie - França e Universidade Federal do Rio Grande do Sul)

** Maitre de conférences. Faculdade de Direito e de Ciências Sociais de Poitiers

1 Thémis ou bibliothéque du jurisconsulte, 1819-1831; WARNKOENIG, De "état actuel de la science du droit en Allemagne et de la réiolution qu'elle y a éprouvée dans le cours des trente dernières années, Thémis, t. I, 1819, pp. 7 e s.; REMY, La Thémis et le drait naturel, RHFD 1987, p. 145; deve-se, no entanto, ser judicioso e evitar apresentar a Thémis de modo excessivamente radical como a voz de Savigny na França; WITZ, Drait privé allemand, Litec, $1992, \mathrm{n}{ }^{\circ} 4$

${ }^{2}$ LABOULAYE, Essai sur la rie et les doctrines de Frédéric Charles de Sarigny, 1842; ALAUZET (Isidore), Historne de la possession et des actions possessoires en droitfrançais, 1846, que enaltece "as magníficas explanações em matéria de interditos possessórios"; MOLITOR, Cours de droit romain approfondi, La possession, la revendication, la publicierne et les seritudes en droit romain, curso proferido em Gand, Paris, 1852, que avalia a sua obra nestes termos: "antes do surgimento do erudito tratado de Savigny, uma confusão extrema reinava em matéria de posse no direito romano".

${ }^{3}$ LERMINIER, De Possessione analy tica sarignyaniae doctrinae expositio, 1827

${ }^{4}$ Vide as explicações trazidas por Jean GAUDEMET, Histoire et système dans la métbode de Sanigny, in Hommage à René Dekekers, Bruylant, 1982, pp. 117-113, sobretudo in fine.

${ }^{5}$ Vide MOTTE, Sarigny et la France, Berna, Lang, 1983;

${ }^{6}$ SAVIGNY, Das Recbt des Besitzes: Eine cirilistische Abbandlung, Heyer, 1803. Vide http://dlib-pr.mpier.mpg.de; WARNKOENIG Analyse de lourrage : le droit de la possession, traité dé droit civil de F. C. de Sarigny, Thémis, t. III, 1821, pp. 224-235 e 45-460, assim como
} 
um pouco em seguida. Deve-se estar ciente de que, apesar da aparente dificuldade técnica da matéria - que não foi escolhida por acaso pelo próprio jovem Sanigny em 1803 - $^{7}$ o tratado sobre a posse e suas edições sucessivas não constituem apenas uma teoria dos direitos reais e do direito de propriedade, mas uma perspectiva mais ampla, uma visão da conexão histórica entre as fontes romanas, o direito medieval e o sistema jurídico moderno. Na segunda metade do século XIX, a difusão do System e de sua tradução, bem como da tradução do Direito das obrigaçoeses renovarão o interesse da doutrina francesa pelas teses de Savigny, muito mais pela sua própria força, devese dizer, que como contraponto às teses de Jhering.

Para medir a profundidade das pegadas deixadas por Savigny na literatura civilista francesa, demonstrarei as marcas deixadas pelas duas obras de direito civil que se encontram nas extremidades de sua vida científica, ${ }^{9}$ sucessivamente e cronologicamente pelo Tratado da posse (1803) e, em seguida, pelo Direito das obrigaçoes (1851-1853).

\section{I - A Posse}

\section{Pontos-chave}

A tese de Savigny acerca da posse em direito romano tem por fio condutor a autonomia conceitual da posse em relação à propriedade; não nos devemos deixar surpreender, inicialmente, pela dificuldade de recepção do sistema proposto por Savigny, uma vez que a tradição civilista francesa do início do século XIX trata a posse como constitutiva de uma presunção de propriedade. Assim, subsiste o fato de que Savigny empreende uma análise factual e subjetivista das condições da posse que coincidirá com as opiniões de uma parte da doutrina no início e no intermédio do século XIX. ${ }^{10}$

$1^{\circ}$. A teoria da posse de Savigny repousa, de início, na definição de detenção, sobre o fato de deter o corpus. Esse fato de deter não é a posse em si mesma, mas apenas sua condição necessária. "Toda aquisição de posse funda-se em um ato corporal (corpus ou factum), acompanhado de certa vontade (animus). $\mathrm{O}$ ato - factum - deve pôr aquele que deseja adquirir a posse em uma posição tal que apenas ele possa dispor da coisa ao seu bel-prazer, ou seja, agir, em relação a ela, como proprietário. A vontade deve tender a tratar também a coisa em realidade como uma propriedade; de modo simples, uma vez que a posse é derivada da posse anterior de outrem por força de um fato jurídico, é suficiente querer essa transmissão, de sorte que a posse pode, então, ser adquirida ainda que se reconheça a propriedade de uma outra pessoa". ${ }^{11}$ Por meio dessa formulação, Savigny anuncia a condição suficiente à existência da posse, o animus, e induz, assim, o primado da vontade sobre o fato de deter.

Thémis, t. IV, 1822, pp. 234-256, Thémis, t. V, 1823, pp. 345-366 e 468-477, onde Warnkoenig expõe a teoria dos interditos possessórios mencionando que a quarta edição da obra contém muitas idéias novas; deve-se observar também que a teoria de Savigny evoluiu de edição em edição; vide BRUTTI, L'intuizione della proprietà nel sistema di Sarigny, Quad. Fior. 5/6, 1976/77, t I, pp. 41-103, sobretudo p.77; do mesmo modo, PEDAMON, Le code civil et la doctrine juridique allemande du XIX siècle, in Le code ciril: 1804-2004: un passé, un présent, un avenir, Ed. Panthéon Assas, 2004, pp. 803 es.

${ }^{7}$ Vide Peter STEIN, Roman lan in Eumpean history, CUP, 1999, pP. 115 e s, sobretudo p. 119.

${ }^{8}$ SAVIGNY, Das Obligationenrecht als Theil des beutigen romischen Recbts, 1851-1853; trad. franc. de Gérardin e Jozon, Le droit des oblizations, 1863 ( $2^{2}$ ed., 1873); republicado por LGDJ - coleção Faculdade de Direito de Poitiers, 2008.

${ }^{9}$ Para uma apresentação completa, vide JoUANJAN, Une bistoire de la pensée juridique en Allemagne (1800-1918), PUF, 2005, pp. $11 \mathrm{ss}$.

${ }^{10}$ Vide, sobretudo, a análise feita por ZENATI-CASTAING e REVET, Les biens, 2008, para aprofundamento, n. ${ }^{\circ} 447$, pp. 651 es

11 Traité de la possession en droit romain, trad de Faivre-d'Audelange, 1842, \$XIII, p. 207. 
A teoria torna-se mais complexa quando Savigny identifica dois aspectos do corpus. para adquirir a posse, a condição de corpus traduz-se pela potencialidade de uma apreensão física da coisa; ver uma coisa pode ser suficiente, ainda que sobre essa coisa se pudesse efetivamente exercer o poder daquele que a apreende. Inversamente, a conservação da posse não mais requer essa proximidade física e corporal necessária à aquisição da posse; a vontade de possuir mantém, por si só, um corpus potencial (ou fictício), mesmo a despeito do distanciamento da coisa e da perda do controle sobre ela. Segundo ele, "a primeira condição da continuação da posse consiste em uma relação física com a coisa possuída, relação que nos permite exercer sobre ela a nossa ação. Mas não é minimamente necessário, como para a aquisição da posse, que essa faculdade seja imediata, atual; basta que essa relação permita-nos obtervolitivamente um poder imediato, e dessa maneira a posse não se perde, a menos que a ação de nossa vontade se tome efetivamente impossível. Essa regra será aplicável tanto às coisas móveis quanto imóveis". ${ }^{12}$ A vontade mantém a posse quando a detenção tiver cessado.

$2^{\circ}$. O animus de Savigny conforma a segunda grande tese de seu Tratado. Como demonstrado pelo Professor TRIGEAUD, essa condição de intencionalidade tem ela também um teor ambivalente em razão da variabilidade do corpus e dos efeitos jurídicos conferidos à posse. Primeiramente, trata-se da vontade de deter, ou seja, de unir à detenção material da coisa a vontade de ter sobre ela o controle, ${ }^{13}$ mas "apenas merece o qualificativo de possuidor [aquele que] trata como proprietário a coisa que detém, ou seja, que quer dela dispor de fato do mesmo modo que um proprietário dela dispõe em virtude de seu direito e, por conseqüência, não quer reconhecer a superioridade de nenhum direito alheio". ". Assim, se a vontade deve ser dirigida a tratar também a coisa, em realidade, como uma propriedade, ${ }^{15} \mathrm{O}$ animus é, "ao mesmo tempo, consciência do corpus, vontade de realizá-lo, de haver para si a coisa em que consiste, enfim, consciência dessa vontade mesma". ${ }^{16}$ Esse comportamento de proprietário como condição da posse, no entanto, tem um fim: tornar-se proprietário. $\mathrm{O}$ animus domini não converge, segundo Savigny, para um sentimento ou crença de ser proprietário; pelo contrário, o animus domini é vontade de fazer da coisa propriedade sua. ${ }^{17}$ Factualmente, no entanto, isso não é instantâneo. Para que a posse seja conservada, o animus de tornar-se proprietário deverá ser mantido e renovado a todo instante, até a prescrição, mas "a circunstância de que o possuidor, durante um tempo mais ou menos longo, não se desligue da coisa e, por conseqüência, da posse, não implica que ele perca esta última." ${ }^{\prime 18}$ Somente um animus contrário ao animus inicial fá-lo-á perder sua posse. "A posse se perde, assim, somente pelo animus, no momento qualquer em que o possuidor a ela queira renunciar; porque, nesse momento, a reprodução da vontade originária torna-se radicalmente impossível pela manifestação contrária da vontade."

\footnotetext{
12 XXXI, pp. 372-373, vide a modificação de tradução proposta por TRIGEAUD, La possession des biens immobiliers, 1981, p. 47 ${ }_{13}$ TRIGEAUD, op. cit., p. 115.

${ }^{14} \mathrm{SIX}$, p. 103.

15 XIII, p. 207.

16 TRIGEAUD, op. cit, p. 116

${ }^{17} \mathrm{SXX}$, p. 259.

${ }^{18} \$$ XXXII, p. 392
} 
No entanto, explica Savigny, se a vontade deve tender a tratar a coisa em realidade como uma propriedade, "uma vez que a posse é derivada da posse anterior de outrem por força de um fato jurídico, basta querer essa transmissão, de sorte que neste momento a posse pode ser adquirida, ainda que se reconheça a propriedade de uma outra pessoa". ${ }^{19}$ Com isso quer-se dizer que um possuidor que tenha o animus domini pode, por meio de um ato jurídico, entregar a coisa às mãos de um novo possuidor, que terá vontade de ter a coisa mesmo que como possuidor de segunda ordem, reconhecendo a vocação do primeiro à propriedade. $\mathrm{O}$ corpus é, portanto, realizado pelo possuidor derivado, o animus domini permanece com o possuidor originário; e, portanto, o detentor da coisa não na possui para si, mas para outrem.

$3^{\circ}$. A natureza do direito do possuidor é, para Savigny, a terceira questão inevitável do Tratado. A grande idéia reside na autonomia conceitual da posse em relação à propriedade. Ao afirmar que a posse resulta de um simples fato, complementado pela condição psicológica do detentor, movido por uma intenção de ser proprietário, a determinação do direito do possuidor remete-se a uma controvérsia clássica à época. " ${ }^{20}$ A posse deve ser considerada um direito? É ela ius in re?"21 Contrapondo-se à doutrina dominante, Savigny desfere diversos golpes contra a tese realista do direito do possuidor: enquanto fato, a posse não confere nenhum direito sobre a coisa possuída, ela autoriza, simplesmente, a ação em justiça pela reparação de um prejuízo em caso de desapossamento violento. Desse modo, a natureza do direito do possuidor é determinada pelo regime das ações possessórias (ou dos interditos possessórios em direito romano) que lhe permitam recobrar sua posse. A coisa do verdadeiro proprietário não é gravada com um direito real do qual o possuidor será titular, pois a propriedade pode ser reivindicada por via petitória. Apenas em caso de violência ou vias de fato cometidas contra o gozo pacífico da coisa possuída assiste ao possuidor uma ação de reparação. Não é qualquer direito real de posse que possibilita essa ação em justiça, é o delito constituído pela turbação causada à posse. Dito de outro modo, Savigny nos ensina que o possuidor só tem direito a partir do momento em que ele foi violentamente privado de sua coisa. Ele não tem um direito real, ele tem um crédito de reparação.

"O direito dos interditos possessórios pertence, portanto, ao direito das obrigações, e aí se fala da posse enquanto componente da condição essencial dos interditos. $\mathrm{O}$ ius possessionis, ou seja, o direito que confere a simples posse, consiste simplesmente no fato de que o possuidor pode reclamar os interditos desde que intervenha um ato violento contra sua posse. $\mathrm{Na}$ ausência dessa violação, a simples posse não confere nenhum direito, nem um ius obligationis, o que é bem evidente, nem um direito sobre a coisa, pois nenhum ato dirigido à coisa deve ser mantido como legal apenas porque quem agiu tinha a sua posse."

Para Savigny, a posse continua sendo uma anomalia durante um período de transição: as ações e interditos possessórios protegem o possuidor e sua usucapião em curso, mas não reconhecem nenhum direito enquanto a prescrição aquisitiva não se tiver consumado; o verdadeiro proprietário não perde seu direito aos poucos, este é sempre uno, ao que ele deve

${ }^{19} \mathrm{SXIII}, \mathrm{pp} .207-208$

20 TOULLIER, Droit civil frangais suivant londre du Code, III, 1811

21 I, p. $5 ; \S$ VI, p. 29 
reivindicar a coisa para obter a sua restituição judiciária, único desapossamento válido. A posse "não é nem mesmo um direito por si só", diz-nos Savigny, e, por conseqüência, "a posse pertence ao direito das obrigações".

\section{Ponto de vista}

Os três aspectos principais da teoria de Savigny que acabei de descrever - para cujo aprofundamento apenas posso remeter à obra magistral do Professor TRIGEAUD, La possession des biens immobiliers - articulam, grosso modo, uma concepção subjetivista e voluntarista da posse. ${ }^{22}$ No prefácio de sua obra, Savigny não hesita em apresentar-se como um inovador, e sua influência também deve ser medida em função das novidades trazidas pelo Tratado. Entretanto, como seus críticos observarão, tão logo suas teses sejam amplamente difundidas na Europa, a concepção de Savigny não era tão inovadora quando se pretendeu. A imagem de um Savigny sozinho contra todos os demais, extirpando a posse dos tenebrosos de uma má intepretação dos textos romanos seria muito exagerada. E se as suas idéias já estavam presentes em Doneau ou Cujas, sob formas aparentadas e não-sistematizadas em Domat ou Pothier, como enfatizará Jhering, poder-se-ia perquirir acerca da influência real da obra de Savigny; devemos ficar menos surpiesos ao constatar, assim, que a doutrina francesa do século XIX foi sensível às proposições de que ela já compartilhava. ${ }^{23}$

\section{Poucos vestígios ou nenhuma marca antes de $\mathbf{1 8 4 0}$}

Ao realizar minhas pesquisas, esperava encontrar cada vez mais referências à obra de Savigny; sabendo que os grandes trechos traduzidos por Warnkoenig haviam se beneficiado da difusão da Thémis, que autores importantes haviam declarado sua empatia pelas teses e o método de Savigny, pensei, ingenuamente, que encontraria facilmente vestígios do Tratado da posse. O resultado é decepcionante: antes de 1840, época das traduções completas da obra, há pouquíssimas referências, que são feitas apenas à tradução-análise de Warnkoenig, nenhuma referência à obra original. Deveria, no entanto, procurar melhor para encontrá-las; esse trabalho arqueológico, de certo modo, apenas começou.

PROUDHON (Traité des droits d'usufruit, d'usage..., t. VIII, n. ${ }^{\circ} 3530$ et seq.), DELVINCOURT (t. II, 1834, pp. 209 et seq.), TOULLIER (t. III, 1824; t. XI, 1830) e DURANTON não parecem fazer referência direta à obra, não mais que os processualistas - os procedimentalistas, como se dizia, preferencialmente, à época-BONCENNE \& BOURBEAU, CARRE \& CHAUVEAU ou BOITARD. Além do mais, esses diferentes autores embasavam a maior parte de suas demonstrações teóricas, no caso dos primeiros, e práticas, no caso dos últimos, sobre a idéia de que a posse confere ao possuidor um direito real sobre a coisa possuída. Tal afirmação é incompatível com a essência da tese de Savigny. "Mas em razão de a posse constituir um verdadeiro direito e um direito bastante importante para o possuidor, este deve dispor de uma ação, seja para reivindicá-la quando dela foi despojado por outrem, seja para conservá-la quando se lha turba; daí as ações possessórias de que nos devemos por ora ocupar."24

\footnotetext{
22 TERRE e SIMLER, Les biens, $5^{\text {a }}$ ed, $1998,11 .^{\circ} 160$; o Código Civil era menos voluntarista em matéria de posse que seus intérpretes, ZENATI-CASTAING e REVET, op, cit, $\mathrm{n} .^{\circ} 448$

${ }^{23}$ TRIGEAUD, op. cit, p. 145.

${ }^{24}$ PROUDHON, Traité des droits d'usufrutt, d'usage,.., t. VIII, 1825, n. ${ }^{\circ} 3529$
} 


\section{Ponto de convergência}

Encontra-se, por outro lado, em BIOCHE, autor de um importante Dicionário de procedimento civil e comercial (vide o verbete "ação possessória"), uma referência aos artigos dedicados por Warnkoenig ao Tratado da posse, ${ }^{25}$ seria bastante temerário cogitar de qualquer influência, apesar de a breve definição de posse apresentada ter traços conhecidos; BIOCHE, no entanto, não desenvolve uma teoria da posse. "Possuir uma coisa é tê-la em seu poder, seja detendo-a por si mesmo, seja fazendo-a ser detida por outrem (Cód. Civil, Art. 2228). A detenção é o ato corporal através do qual se captura ou se retém uma coisa. Em linguagem vulgar, esse fato é freqüentemente confundido com a posse; mas a posse exige, além do fato material da detenção, a vontade de ser proprietário. A posse é, portanto, a detenção a título de senhorio. A ausência do possuidor não é suficiente, de modo geral, para tornar a posse vacante; ela subsiste em seu benefício. Assim, diz-se com razão que a posse não se perde corpore solo, que ela se conserva animo solo. Mas é necessário atentar para não estender demais a aplicação desse princípio (à hipótese de um desapossamento violento por fato de terceiro)." Após fazer referência a Savigny-Warnkoenig, BIOCHE deixa transparecer que aquilo que é verdadeiro para o direito romano não no é para o direito francês, exatamente em razão do regime da ação possessória. As marcas de Savigny são, em conclusão, pouco profundas; sãono mais em TROPLONG.

6. No seu comentário ao Título XX do Livro III relativo à Prescrição, TROPLONG consagra sua análise ao exame das diferentes teorias da posse; ${ }^{26} \mathrm{o}$ autor faz uma exegese crítica dos artigos 2219 e seguintes do Código Civil, remetendo-se ao direito romano enquanto sistema de interpretação comparado, e reserva um lugar importante para o Tratado de Savigny. ${ }^{27}$ Já no prefácio ele assim anuncia: "Nos últimos tempos, surgiu na Prússia um livro que granjeou sucesso em âmbito europeu, quero falar do Tratado daposse de Savigny; é uma obra de grande alcance, na qual se admira o mais exato conhecimento dos textos, bem como a agudeza do autor ao examiná-los com a dupla autoridade da análise e da história; não creio, no entanto, que essa bela obra possa exercer uma influência real sobre o direito francês e modificar quaisquer aspectos de nossas idéias sobre a posse, base da prescrição, bem como acerca das ações possessórias, que dela derivam. Savigny elaborou um livro tipicamente romano; não quis desviar-se do horizonte de Gaio, Ulpiano e Triboniano: o nosso é necessariamente diferente. ${ }^{28}$ Diferente a ponto de Troplong também sustentar que, segundo a doutrina do Código Civil, os detentores precários são também possuidores, de modo que toda detenção seria uma posse; esse posicionamento isolado entre os comentadores do Código, incompatível com a tese de Savigny, dará lugar a uma longa anti-tese elaborada mais tarde por Marcadé. ${ }^{29}$ Troplong tem um horizonte bastante diferente daquele de Savigny, em virtude de uma originalidade bem nacional, como ele insiste, mas adota uma perspectiva próxima: ele atribui a Savigny os esclarecimentos que se fizeram acerca das antigüidades romanas, mas

\footnotetext{
${ }^{25}$ T. I, $2^{\mathrm{a}}$ ed., 1839 (p. 143, n. ${ }^{\circ}$ 71); citando Thémis, 3-224, 445; 4-234; Savigny-Warnkoenig, $2^{\circ}$ artigo.

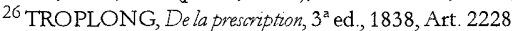

${ }^{27}$ Desde 1835, por meio da exposição de LERMINIER, De Possessione analytica sazignyaniae doctrinae expositio e WARNKOENIG, Thémis, t. V, p. 345.

${ }^{28}$ De la prescription, Prefácio, p. XI

${ }^{29} \mathrm{MARCADE}$, Explication du titre XX du live III du code Napoléon contenant 't anabyse critique des auteurs et de la jurisprudence, 1854, Art. 2228
} 
constata que os textos franceses, já há bastante tempo, haviam reformado a natureza e teor dos direitos do possuidor. Para Savigny, por exemplo, os interditos possessórios não tinham, em Roma, o efeito de presunção de propriedade; Troplong quer admitir esse fato, mas observa que no direito francês isso se dá de modo diverso: "ele não é um autor antigo ou moderno, que só ensina que nossa posse ânua (desconhecida do resto dos romanos) é, para o possuidor, fonte de uma presunção de propriedade que o dispensa de qualquer prova, salvo se o contrário for evidente. Esse é o ponto de partida que jamais se deve perder de vista para que não nos percamos ao comparar nosso sistema da posse com aquele dos romanos". ${ }^{30}$

De certo modo, Troplong explica-nos que a obra de Savigny confronta-se com uma dificuldade de recepção resultante do fato de que o regime das ações possessórias (de direito positivo) determina a natureza da posse e impõe que se a considere como uma presunção de propriedade. Dito de outro modo, se as teses de Savigny sobre a posse não conseguem vencer esses obstáculos de incompatibilidade nacional, não serão passíveis de admissão. ${ }^{31}$

Por outro lado, depreende-se igualmentes dessas exposições, e mesmo daqueles que parecem deliberadamente esquecer Savigny, como a tradução francesa do manual de ZACHARIAE realizada por Aubry e Rau, ${ }^{32}$ que os conceitos provenientes do direito romano foram modificados por um processo histórico que marca, doravante, a sua especificidade.

Menos surpreendentemente, não se encontram muitas referências a Savigny nos tratados generalistas de direito civil antes de 1840; à exceção de Troplong, cujo método e estilo revelarn a influência tanto da diluição do discurso quanto da profundidade de uma interpretação histórico-romanista, os mestres de direito civil (e mais ainda de direito processual civil), autores dos primeiros comentários, inspiraram-se apenas em fontes literárias de tradição francesa, se é que poderiam ser consideradas romanistas. ${ }^{33}$ À primeira vista, a universalidade da teoria da posse de Savigny mostra-se evencida justamente por aquilo que lhe confere força; a concepção de um direito como função do espírito nacional, como capacidade da nação de dotar-se de regras, conduz a dissociar o direito civil nacional francês - de Cujas, Domat, Pothier e do Código Civil - do direito romano, e torna este último nada mais que um conjunto de disposições passíveis de aplicação, conquanto sistema de interpretação exterior ao direito nacional. Em virtude disso, exime-se a posse romana das análises "francesas". Por meio de um efeito negativo, o método histórico conduz a descartar o direito romano em favor de uma concepção nacional da posse. ${ }^{34}$

${ }^{30}$ Dela prescription, pp. 346-347

31 De la prescription, p. 360: "demonstraremos a esses estimáveis sábios, em demasia preocupados com o poder do direito romano, que o direito francês também tem suas liberdades e sua originalidade e que não é filosófico querer tudo cunhar de uma forma exclusiva, adivinhada antes que redescoberta, em elucubrações solitánas"; acerca do texto de Warnkoenig sobre Savigny, vide Thémis, t. V, p. 345

${ }^{32} \mathrm{ZACHARIAE}$, AUBRY e RAU, Cours de droit azizlfrançais, t. I, $2^{2}$ ed., $1843, \S 182$, não parecem fazer referência em notas de rodapé a Savigny, se bem que Zachariae (1808) refere-o na primeira edição de seu Handbuch, \68, p. 102 (http://dlib-mpier.mpg.de), e também nas edições subseqüentes; de modo contrário, as edições francesas ignoram-no na bibliografia elencada no $\ 184$. O mesmo ostracismo verifica-se nas edições subseqüentes, onde Jhering aparece; conclui-se que a teoria da posse de Zachariae é, de fato, compatível com aquela de Savigny.

33 Vide CAROU, Traité théorique et pratique de procédure cizile, 1838; o autor copia, de fato, Troplong; ao que não pode ignorar as referências feitas por este ao Tratado da posse de Savigny. Carou nada faz, permanece convicto de que a posse é emanação da propriedade e que os interditos e ações possessórias são ações que sancionam a violação do direito do possuidor.

34 Os críticos de Troplong, onde se insere, em primeiro plano, Marcadé permanecem também inclinados a determirar o espírito 


\section{Ponto de mudança}

A virada dos anos 1840 concentra diversos fatores de mutação. De um lado, os estudos filológicos e a pesquisa das interpolações assumem tal amplitude que parece impensável, a partir de então, estudar o direito do digesto e das institutas sem se indagar sobre a origem e a fonte histórica das regras. $\mathrm{O}$ trabalho dos anti-tribonianos rende seus frutos e conjuga-se com a vontade reafirmada dos grandes romanistas franceses e francófonos de conjugar-se aos esforços de Savigny. Laboulaye, em $1842,{ }^{35}$ assim como em $1855,{ }^{36}$ carregará a bandeira da renovação dos estudos de direito com o fim declarado de constituir, em torno $\mathrm{d}$ a redescoberta do direito romano, a base de um conhecimento comum aos povos europeus. A criação da sociedade de legislação comparada, em 1869, servirá a esses esforços.

Com o romanista Molitor aprendemos que "antes do surgimento do erudito tratado de Savigny, uma confusão extrema reinava em matéria de posse no direito romano", e lê-se dos escritos de Ortolan ${ }^{37}$ que "Savigny publicou, na Alemanha, um tratado acerca da posse a cuja reputação meus elogios nada podem somar. Segui, nesses princípios gerais, uma parte de suas idéias, sem adotá-las todas". Pellat, ${ }^{38}$ Demangeat, Machelard servirão também à causa da difusão do System e do pensamento de Savigny.

Nesse período, entretanto, época em que apesar de os civilistas fanceses estarem atentos à doutrina romanista (uma vez que os candidatos à carreira universitária redigem duas teses, uma delas em direito romano), por motivos diversos, serão poucos aqueles a terem concebido uma teoria da posse: $:^{39}$ o comentário, artigo por artigo, parece não permitir a expressão de uma visão geral da posse. O Artigo 2228 do Código Civil chega, de certo modo, tarde demais aos exegetas. Poderíamos ter pensado que Marcadé havia evocado o Tratado da posse de Savigny, o que não ocorreu; nem Démante, nem Demolombe, nem Laurent. ${ }^{40}$ Mesmo em Aubry e Rau a referência feita à posse segundo Savigny por Zachariae é apagada por seus tradutores. ${ }^{41}$ No entanto, todos esses autores desenvolvem ou adotam análises voluntaristas e factualistas da posse; eles rejeitam a idéia segundo a qual a posse confere um direito real sobre a coisa de outrem e sustentam, contra Touiller e Duranton, que a posse é um fato, que corpus e animus são necessários para que o detentor torne-se possuidor, segundo os argumentos que Savigny poderia ter por si mesmo explicitado, mas permanecem vinculados à idéia francesa de que a posse cria uma presunção de propriedade.

do Código Civil. Marcadé rebate vivamente Troplong acerca da questão de saber se o Código corresponde, em matéria de posse, às doutrinas de Pothier, Troplong afirma que sim, Marcadé inão hesita em polemizar e mesmo em ressaltar que a doutrina do sábio magistrado é inteiramente falsa (Art. 2228) ao recorrer à análise pormenorizada das fontes francesas da posse.

${ }^{35}$ LABOULAYE, Essai sur la zie et les doctrines de Frédéric Charles de Sartigny, 1842.

${ }^{36}$ BOUDOT, Les programmes scientifiques des revzes juridiques des $19^{e}$ et $20^{e}\left(\right.$ et $\left.21^{e}\right)$ siècles, in Augustin e Gazeau, Coutumes, doctrine et droit savant, LGDJ, 2007, pp. 307-318.

${ }^{37}$ ORTOLAN, Instituts de Justinien, t. II, $6^{a}$ ed., 1857, p. 259, nota 2

38 PELLAT, Exposé des principes généraux sur la propriété et ses principaux démembrements, $2^{\mathrm{a}}$ ed., 1850.

${ }^{39}$ Como tratado monográfico, no entanto, BELIME, Traité du droit de possession et des actions possessoires, 1842; a obra é de dificil acesso, mas existe uma tradução italiana em google books, Trattato del diritto di possesso, 1856.

${ }^{40}$ LAURENT, Principes de droit citil franģais, t. XXXII, $3^{2}$ ed, 1878 , Art. 2228.

${ }^{41}$ No entanto, não desejo ser peremptónio, pois, nessa busca arqueológica, a descoberta de todos os traços seria útil, e a biblioteca de Poitiers não dispõe de todas as edições das obras do século XIX; seria infinitamente grato, portanto, a todos aqueles que, por força de pesquisas pessoais, descobrirem quaisquer preciosidade em relação a Savigny - uma vez que possa ter deixado de assinalar diversos traços. O contato é fácil: mboudot@univ-poitiers.fr. 


\section{Apogeu}

Se se deve ressaltar uma evolução no modo de compreender Savigny entre os anos 1830 e 1860, podemos nos debruçar sobre o Repertório de Dalloz. Na edição de 1827$1830,{ }^{42}$ nos verbetes ação possessória e prescrição, a seção 2 , relativa à explicação acerca da posse, faz menção às teses de Delvincourt e Touiller, sem referir a tese de Savigny; o discurso é parcimonioso em teorias. De modo contrário, na edição do mesmo repertório, datada de 1845-1856, ${ }^{43}$ faz-se menção rápida ao Tratado da posse a propósito das ações e interditos possessórios, no que concerne à posse mesma, que é explicada no verbete prescrição. O Dalloz primogênito faz, em nota de rodapé, um resumo que entende ser completo a respeito do tratado de Savigny: "essa análise provém de uma obra bastante reconhecida na Alemanha, o Tratado da posse em direito romano de Savigny. [...] No entanto, essa teoria, cuja análise foinos enviada por um jurisconsulto amigo, a qual ele nos permite imprimir nesta obra, não responde às questões mais difíceis, impossíveis de não apresentar quando se se ocupa da posse. - Por exemplo, a posse é anterior à propriedade?". ${ }^{44}$ Sem rechaçar a adesão de Dalloz, a difusão do Repertório irá aumentar consideravelmente a exposição da tese de Savigny.

Se isso não basta para demonstrar sua influência, ressalte-se que a tese de Savigny se tomará compatível com certas concepções no intermédio do século XIX; e isso explica o fato de os autores do início do século XX verem a tese de Savigny como dominante no século XIX.

\section{A virada do século $\mathrm{XX}$ na mira}

Se continuarmos a empreender esse excursionismo diacrônico, perceberemos uma notável mudança nas obras de direito civil no momento em que a teoria da posse de Savigny não mais é tratada como uma teoria do direito romano, mas sim como uma tese (aliás, a mais freqüentemente combatida) integrada à teoria geral da posse. Aí repousa, sem dúvida, o maior sucesso de Savigny. Observemos, com efeito, que no fim do século XIX a doutrina francesa concebe teorias gerais, ${ }^{45} \mathrm{e}$ que a discussão erudita confere ao direito romano a qualidade de direito comum a todos os povos. ${ }^{46}$ Esmein,${ }^{47}$ Bufnoir ${ }^{48}$ Saleilles, ${ }^{49}$ Planiol, Capitant não mais apresentam a teoria romana da posse de modo dissociado da teoria moderna, o que indica, de um lado, a assimilação do método histórico (ou seu avatar francês) por esses autores. Deve-se assinalar, no entanto, que as referências à obra de Savigny são feitas principalmente sob o exame da controvérsia introduzida por Jhering, e é este último que terá o apoio dos titulares da escola da livre pesquisa científica. ${ }^{50}$ Segundo Jhering, cuja teoria objetiva não se embasa no animus domini, mas na causa possessionis, para constituir a posse, basta ter a intenção de criar e conservar uma relação com a coisa, exercendo um poder de fato

\footnotetext{
42 Jurisprudence générale du Royaume, ou Répertoire méthodique de la législation et de la jurisprudencefrançaise, t. I, 1827, verbete action possessoire et XI, 1830, verbete prescription.

${ }^{43}$ Répertoire métbodique et alphabétique de la légisiation, de doctrine et de la jurisprudence, t. III, verbete action possessoine, 1846, t. XXXVI, verbete prescription, 1856

${ }^{44}$ Verbete prescription, $\mathrm{n} .{ }^{\circ} 236$

${ }^{45} \mathrm{JAMIN}$, Un modèle ongiginal, la construction de la pensée juridique frangaise, http://www.courdecassation.fr/BICC/.

${ }^{46}$ CORNIL, Traité de la possession en droit romain pour serrir de base à une étude comparative des législations modernes, 1905

${ }^{47}$ ESMEIN, Les theories de la possession en Allemagne, NHR, 1877, pp. 489-500.

${ }^{48}$ BUFNOIR, Propriété et contrat, 1900 , reimpressão, LGDJ, 2005.

${ }^{49}$ SALEILLES, Eléments constitutifs de la passession, 1894; La possession des meubles, 1907

${ }^{50}$ VERMOND, Théone générale de la fossession en droit romain, 1895
} 
sobre ela. A oposição a Savigny torna-se uma oposição à tese dos exegetas e insere-se globalmente em uma vontade de renovação dos métodos de interpretação e das fontes do direito positivo.

Apresentar Savigny como responsável pelo sucesso de Jhering seria exagerar um pouco as coisas, mas, de certo modo, a afirmação e o reconhecimento de sua teoria da posse vêm justificar a argumentação doutrinária em favor de uma concepção objetiva da posse. ${ }^{51}$ Em contrapartida, algo curioso, mas, ao fim, habitual: os opositores da teoria objetiva no início do século XX justificarão a tradição francesa mais subjetivista por meio de uma aproximação das teses sustentadas em direito romano um século antes por Savigny.

No início e ao longo do século XX, as opiniões dos protagonistas da controvérsia Savigny-Jhering sobre os fundamentos da posse estarão desconectadas de um questionamento sobre o direito romano por serem tratadas diretamente-no âmbito da análise do regime positivo da posse. Nesse ponto pode-se notar um sucesso de Savigny, pois, contrariamente a um Troplong, que admitia a pertinência de suas teses em direito romano, mas desqualificavaas em direito positivo em virtude das particularidades nacionais, PICARD ${ }^{52}$ considerá-las-á elucidativas do direito positivo, apesar de não aderir a elas completamente.

O tom persiste pelo resto do século XX, mas, por outras razões, não mais será Savigny que permitirá explicar o direito positivo da posse; a doutrina francesa terá mudado de referencial interpretativo ao abandonar o direito romano (mesmo que renovado pela análise comparatista) em favor de um direito positivo auto-interpretado pela jurisprudência. ${ }^{53}$ Em relação ao direito das obrigações, as mudanças ocorrerão de modo ligeiramente diferente, mas a conclusão será a mesma.

\section{II - O Direito das obrigações}

\section{Parte geral}

No prefácio ao oitavo volume do System, Savigny deixa transparecer que sua obra maior ficará inacabada; fatalista, ele não demonstra crer em que ainda terá tempo de redigir as quatro partes anunciadas (Direito das coisas, Direito das obrigações, Direito de família, Direito das sucessões), mas decide reformar a sua proposta, ao que convida o seu leitor a não na trair: "considero, presentemente, os oito volumes que publiquei uma obra completa, a cujo título devemos adicionar, com o pensamento, Parte geral. Publicarei a parte especial do System não como continuação da parte geral, mas como diversas obras distintas, a começar pelo direito das obrigações, não pelo direito das coisas, como propunha no meu plano primitivo. Estas obras distintas parecerão ter a forma exterior de monografias, sem delas resguardar o caráter essencial, que defini no primeiro volume; e serão escritas absolutamente do mesmo ponto de vista que teriam sido escritas não tivesse eu em nada modificado meu

\footnotetext{
51 PLANIOL, Traitéélémentaire de droit cizll, t. I, n. ${ }^{\circ} 2311$; vide, igualmente de modo conciso, HUC, Commentaire théorique et pratique du Codecirit, t. XIV, p. 427 e p. 463

${ }^{52}$ PLANIOL, RIPERT e PICARD, Traité pratique de drott civil, t. III, n. ${ }^{\circ} 143$ e s.

${ }^{53}$ BOUDOT, Le dogme de la solution unique, Tese, Aix-en-Provence, 1999.
} 
plano".${ }^{54}$ Esse anúncio relativamente à publicação que se seguiria do Direito das obrigaçôes teve efeitos imediatos; ${ }^{55}$ seus dois volumes foram publicados em 1851 e 1853 , e verificaremos que, ao buscar as marcas deixadas pelo Direito das obrigaçôes, encontraremos, necessariamente, aquelas deixadas pelo próprio Sistema. ${ }^{56}$ Elas são, aliás, numerosas: teoria da personalidade jurídica, ${ }^{57}$ teoria dos direitos subjetivos, ${ }^{58}$ teoria do ato abstrato. ${ }^{59}$

O conceptualismo de Savigny e o espírito do Sistema tiveram particular repercussão ${ }^{60}$ e infiltram-se, forçosamente, no pensamento civilista francês quando começa a manifestar-se a questão da recodificação do Código Civil. Sob a influência dos romanistas, mas também sob a égide dos civilistas - com comparatistas encabeçados por Bufnoir, a doutrina francesa aventura-se em elaborar teorias gerais no seio das quais o conceito romano posa como referencial interpretativo, e o direito romano, no seu todo, mostra-se como um sistema de interpretação diferenciada. ${ }^{61}$ Ao longo do século XX, o espírito das teorias gerais subsistirá, mas a referência romanista desaparecerá, pouco a pouco, da literatura civilista; o que constituiu, sem dúvida, um dos verdadeiros sucessos de Savigny, ou seja, ter convencido a doutrina a utilizar os recursos interpretativos contidos no direito romano para aplicar os direitos nacionais, adquirirá, na França, a triste cor da deserdação científica dos estudos de direito romano.

\section{Parte especial}

O Direito das obrigações não desperta o mesmo interesse histórico que o Tratado da posse, pois, mesmo que considerado a mais perfeita realização de Savigny, ${ }^{62}$ ele se situa em um momento histórico onde a essencialidade dos ensinamentos do jurista já foi ouvida e recepcionada. Ele não tem o poder fundador dos primeiros textos, e seus discípulos franceses não mais são jovens ávidos por reconhecimento científico. Mesmo assim, terá um lugar notável durante os anos 1880-1910, em razão de sua coincidência com a atenção dispensada pelos juristas franceses aos trabalhos preparatórios do Código Civil alemão. Constituirá um dos pontos de partida da renovação dos conteúdos e do tratamento, como um todo, da noção de obrigação. Savigny aborda, na obra, a matéria relativa às obrigações por meio de

\footnotetext{
${ }^{54}$ SAVIGNY, System, Bd. 8., 1849, pp. VIII-IX, trad de Guénoux, 1851, v. 8, pp. 3-4; sobre os legados de Savigny ao Direito Internacional Privado, vide SYNVET, Auant-propos à la rímpression de la traduction frangaise du VIII zolume du System, Ed. PanthéonAssas, 2002.

55 O prefácio ao primeiro volume do Direito das obrigaçöes segue a mesmo linha que aquele ao $8^{\circ}$ volume do Sistema.

${ }^{56}$ Onde Kant se esconderia por detrás do plano dos manuais das Pandectas, vide VILLEY, La doctrine du droit dans l'bistoire de la science juridique, prefácio a KANT, Métapbysique des moeurs, trad. de Philonenko: "pode-se legitimamente falar de uma invasão da ciência jurídica contemporânea pela fisolofia kantiaka. A grande escola pandectista do século XIX, ao elaborar aquilo a que chamou 'Parte geral' do Direito, remodelou as definições de pessoas, de direitos subjetivos, da propriedade, dos contratos, do ato jurídico, etc [...] em uma atmosfera infestada pela filosofia de Kant". Diversamente, no entanto, vide Peter STEIN, Roman lan in eurppean bistory, 1999, p. 123; acerca do programa de Savigny-Puchta e da influência kantiana, vide JOUANJAN, Une histoire de la penséejuridique en Allemagne (1800-1918), pp. 40 e s., 173 e s., 183

${ }^{57}$ Henri CAPITANT, Introduction à l'étude du droit cuzili, 1898, $5^{2} \mathrm{ed}, 1928,11 .{ }^{\circ} 148 ;$ SALEILLES, De la personnalité juridique (Histoire et theories), Rousseau, 1910.

${ }^{58}$ COING, La signification de la notion de droit subjectif, Arch pbil. droit 1964, pp. 1 e s.; GHESTIN e GOUBEAUX, Intraduction gémérale, 1977, n. $^{\circ} 163$ e s., sobretudo n. ${ }^{\circ} 179$; WITZ, op. cit., n. ${ }^{\circ} 572$.

${ }^{59}$ THALLER, De la nature juridique du titre de crédit, Ann. Dr. Commercial 1906, pp. 6 e s., 110 e s., 1907, pp. 9 e s., 97 e s., n. ${ }^{\circ} 133$.

${ }^{60}$ É, no entanto, sobretudo Puchta que carrega a etiqueta de Begriffsyurist. JOUANJAN, op. cit., p. 174.

${ }^{61}$ BOUDOT. Claude Bufnoir (1832-1898), avec les textes pour assises mais au dessus des textes et par dela les textes, apresentação da reedição de BUFNOIR, Propriété et contrat, LGDJ, coleção Faculdade de Direito de Poitiers, 2005.

${ }^{62}$ DEMANGEAT, síntese da tradução francesa de Gérardin e Jozon em RHD, 1863, pp. 379-380.
} 
exposições teóricas da sua natureza, que encontra aplicação às espécies de obrigações previstas a partir de sua fonte:

I. Natureza das obrigações

1. Noção de obrigação

2. Diversas espécies de obrigações

3. Pessoas-parte da obrigação

4. Objeto da obrigação

II. Fontes da obrigação

1. Contrato

2. Delito

\section{Variae causarum figurae}

Esse plano, bastante próximo daquele que Windscheid seguirá, ${ }^{63}$ opõe-se formalmente à maneira de tratar o direito da obrigações segundo a ordem do Código Civil francês. Na primeira parte, Savigny propõe uma teoria da obrigação, uma classificação das obrigações, uma teoria das partes da obrigação, etc. e contempla, apenas na segunda parte, os diferentes regimes de obrigações a partir das suas fontes. É essa maneira de proceder, ecoando o plano do System, que será utilizada para estruturar o BGB. Os seus prefaciadores recomendarnos-ão reter as novas teorias de Savigny relativas às obrigações naturais, às obrigações indivisíveis e solidárias, ao dinheiro, à representação, aos títulos ao portador ou mesmo à natureza dos atos ilícitos. ${ }^{64}$

\section{A impressão}

Naturalmente, a obra receberá uma acolhida bastante favorável por parte dos historicistas que militam em favor da difusão do programa da escola histórica; ela também se dará, no entanto, bastante rapidamente, por meio de referências contidas nos tratados de direito civil. As primeiras referências ao direito das obrigações aparecem em Demolombe; ${ }^{65} \mathrm{e}$, contrariamente à posse, este último terá a oportunidade de esquematizar uma teoria da obrigação no comentário aos artigos 1101 e seguintes, mas o gênero literário e, sobretudo, a limitação do plano do Código Civil não lhe permitirão abordar a obrigação a partir da autoridade de uma teoria geral. Savigny parece ter sido considerado por Demolombe como um autor de referência graças à tradução de Gérardin e Jozon de 1863, e serve-lhe de ponto de referência histórico-comparatista, mas, como seus contemporâneos, Demolombe dissocia ainda direito positivo francês e direito romano. ${ }^{60}$

Nos anos 1880-1890, entretanto, sob a ação conjunta do desenvolvimento dos estudos comparatistas e da focalização de uma grande parte da doutrina francesa no direito alemão, os modos de exposição do direito civil francês serão consideravelmente modificados. Saleilles elabora para o Bulletin de la société de législation comparée um Estudo sobre a teoria geral das

\footnotetext{
${ }^{63}$ Que não será traduzido em francês; contrariamente, vide WINDSCHEID, Diritto delle pandette, 1902.

${ }^{64}$ Prefácio dos tradudores, Gérardin e Jozon, a SAVIGNY, Le droit des obligations, 1863 ( $2^{2}$ ed., 1873).

65 Cours de Code Napoléon, XXIV, 1868, p. 7; outra menção ao System em XXX, 1878, p. 266, a propósito da força da coisa julgada.

${ }^{66} \mathrm{Na}$ dissertação que consagram ao pagamento e às obrigações naturais, BAUDRY-LACANTINERIE e BARDE dispensam atenção particular ao pensamento de Savigny, mas relegam-no à explicação do direito romano, em companhia de Machelard, Accarias e outros romanistas; vide Traité théonique et pratique de droit ciril, Les obligations, t. II, $3^{\mathrm{a}}$ ed., $1907, \mathrm{n} .{ }^{\circ} 1653$ es.
} 
obrigações a partir do projeto do Código Civil alemão (1889). Sua ambição é bastante clara: propor uma reforma do direito civil francês tendo o direito alemão como modelo ${ }^{67} \mathrm{O}$ estudo do direito das obrigações empreende-se pela introdução de uma parte geral consagrada à obrigação mesma e, em seguida, às suas fontes. Ainda é esse o modelo dos manuais das Pandectas adotado por Savigny e Windscheid.

I. Da obrigação em si mesma

1. Objeto da obrigação

2. Efeitos da obrigação

3. Extinção da obrigação

4. Transmissão da obrigação

5. Da pluralidade de credores ou devedores em matéria de obrigação

II. Fontes da obrigação

1. Do ato jurídico considerado como fonte de obrigação

2. Do delito considerado como fonte de obrigação

3. Do enriquecimento sem causa considerado como fonte de obrigação

No mesmo veio dos trabalhos de Saleilles, Marcel Planiol ${ }^{68}$ e Henri Capitant elaboram, o primeiro um tratado, o segundo, um curso elementar cuja primeira parte faz as vezes de parte geral na qual eles propõem, com base no modelo alemão, uma teoria geral dos atos jurídicos, ${ }^{69}$ e uma abordagem das obrigações e de suas fontes em consonância com suas especificidades. A inovação consiste em situar o contrato no campo mais vasto dos atos, embora a teoria dos atos seja apenas uma extensão dos princípios que regem os contratos. ${ }^{70}$

II. As obrigações ${ }^{71}$

1. Efeitos das obrigações

2. Modalidades das obrigações

3. Transmissibilidade

4. Modos de extinção

5. Pluralidade de objetos

6. Pluralidade de pessoas

7. Fontes das obrigações

\$1. Generalidades

Classificação e noções gerais (n. ${ }^{\circ} 805$ et seq.)

Contratos

Quase-contratos

\footnotetext{
67 SALEILLES, Etude sur la théonie générale des obligations d'après le projet de Code aivil allemand, Boletim SLC, 1889, pp. 165 et seg.; Etude sur les sources de lobligation dans le projet de Code cizil allemand, Pichon, 1889; acerca das modificações trazidas ao plano inicial no segundo projeto, vide Etude sur la théorie générale des obligations dans la seconde rédaction du projet de Code ciril pour l'E mpire d'Allemagne, Pichon, 1895, que perfarão, em seguida La théorie générale de lobligation (1ª ed., 1904), LGDJ, $3^{2}$ ed., 1925; De la déclaration de zolonté, contribution à l'étude de l'acte juridique dans le Code cizil allemand, 1901.

68 Acerca da opinião que Planiol tinha do lugar de Savigny na história do pensamento, vide BABERT, Le système de Planiol, Tese, Poitiers, 2002

${ }^{69}$ PLANIOL, Traitéélémentaire de droit civil, t. I ( $\left({ }^{\text {a }}\right.$ ed., 1899-1900), n. ${ }^{\circ} 264$ e s.;

70 De lintêrét de İire attentizement la littérature du tournant du 20 e siècle, vide o ponto de vista trazido por $G$. Rouhette sobre o anteprojeto de reforma do direito das obrigações, in RDCom. 2007, p. 1371.

${ }^{71}$ PLANIOL, Traitéélémentaire dé droit cizil, t. II, (1ªd. 1899-1901), n. ${ }^{\circ} 156$ es
} 
Delitos

Quase-delitos

Obrigações legais

Da vontade unilateral como fonte de obrigações

\$2. Pagamento do indébito

$\$ 3$. Teoria geral da falta

\$4. Do enriquecimento sem causa

\5. Do estelionato

Esse novo plano permite, como prescreve o novo plano de estudos de direito imposto pelo decreto de julho de 1895 (cujo autor foi Bufnoir), estudar o direito civil dissociando uma parte geral das partes especiais. A partir dos anos 1920-1930, no entanto, a doutrina privatista retornará à estrutura clássica para a exposição do direito civil; e, com o tempo, perceber-se-á uma certa diluição das idéias da pandectística, de modo a reencontrar uma leitura acentuadamente mais francesa do direito das obrigações. ${ }^{72}$

\section{Defensores de idéias}

Em nível de detalhe, Capitant, Planiol, Saleilles serão os difusores da pandectística e, por conseqüência, do pensamento de um Savigny cada vez mais afastado, na doutrina francesa, do direito das obrigações: a clarificação das obrigações naturais já havia se dado. A obrigação natural, no sentido romano, estritamente procedimental (obrigação não-sancionada por uma ação, mais passível de ser objeto de pagamento válido) terá expressão dissociada da análise tradicional do dever moral. ${ }^{73}$ Baudry-Lacantinerie parecerá ter apanhado a substancial definição do erro: "de acordo com Donneau, o erro consiste em crer ser verdadeiro aquilo que é falso, e falso, aquilo que é verdadeiro. A definição de Savigny é mais elegante: erro é a falsa noção que temos de uma coisa. A maior gradação do erro é a ignorância, que não é senão ausência de qualquer noção". " Para Planiol, é por meio da teoria da vontade que se reconhecem a influência de Savigny, filtrada por Windscheid, as teorias a-causais, ${ }^{75}$ ou mesmo a concepção teórica dos títulos ao portador. ${ }^{76}$ Planiol se valerá, igualmente, da herança anti-codificadora para compor seu texto contra a recodificação do Código Civil no livro do centenário. ${ }^{77}$

\section{Ponto final}

O tempo diluirá a influência de Savigny, tanto mais quanto a codificação alemã representar, de certo modo, um repúdio à reanálise, e a página será virada. ${ }^{78} \mathrm{Não}$ se dará, no entanto, finalmente a vitória de Savigny? Ele jamais preconizou que o direito local prussiano

\footnotetext{
${ }^{72}$ ANCEL, Acte juridique et de déclarution de volonté: la greffe allemande sur le droit frangais des obligations, in Aristec, Traditions savantes et codiffications, LGDJ, 2007, pp. 161 e s.; BOUDOT, La classification des sources des obligations au tournant du $20^{\circ}$ siècle, in MANNINO e OPHELE, L'enrichissement sans cause, La classification des sources des obligations, $2^{\mathrm{a}}$ e $3^{\mathrm{a}}$ jomadas de estudos Poitiers-Roma Tre, LGDJ, 2007; para indícios da influência de Savigny na common lan; , vide STEIN, op. cit, p. 125.

${ }^{73}$ Já em DEMOLOMBE, XXVII, com o auxílio do discípulo de Savigny Machelard, Des obligations naturelles en droit romain, COLIN e CAPITANT, Cours élémentaire de droit ciril, $\mathrm{t}$. II, 1915, n. ${ }^{\circ} 274$.

${ }^{74}$ BAUDRY-LACANTINERIE e BARDE, $\mathrm{t}$. II, $\mathrm{n}{ }^{\circ} 21$.

75 Windscheid a partir de PLANIOL, $t$. II, n. ${ }^{\circ} 1037$ e s.; vide GHESTIN, Le contrat, n. ${ }^{\circ} 278$ e s.

${ }^{76}$ SALEILLES, La théorie générale de l'obligation, $\ 268$; WAHL, Traité théorique et pratique des titres aux porteurs, 1891.

${ }_{77}$ PLANIOL, L'inutilité d’une réision générale du Code civil, Livre du centenaire, reedição, 2004, p. 955.

78 Vide DEMOGUE, Traité des obligations en général, t. I, Sources des obligations, 1923, cujo interesse refere-se, preferencialmente, à literatura italiana que assimilou os ensinamentos da pandectística.
} 
se impusesse ao resto da Europa; cada povo produz seu próprio direito e, ao longo do século XX, a decodificação progressiva do direito francês das obrigações confirmará, nesse aspecto, a previsão da impossibilidade de isolar, em um Código, aquilo que perfaz o âmago de uma legislação.

Meio século após a morte de Savigny, ao mesmo tempo em que a teoria da posse transportava-se ao pensamento jurídico comum, o direito das obrigações retornava a um quase-anonimato. Um século e meio após a sua morte, ainda se cita a primeira, e ignora-se aquilo que o segundo tinha de inovador e estimulante: a obrigação natural, a obrigação coreal, o dinheiro, a representação, os títulos ao portador. Em tempos de uma reflexão continental sobre o direito das obrigações, uma releitura dos clássicos do direito europeu não faz mal algum. ${ }^{79}$

${ }^{79}$ SAVIGNY, Le droit des obligations, LGDJ, coleção da Faculdade de Direito de Poitiers, a ser publicado em 2008 